\title{
]jfis
}

\section{The Impact on Life Satisfaction of Nursing Students Using the Fuzzy Regression Model}

\author{
Hee Sang Yoon ${ }^{1}$ and Seung Hoe $\mathrm{Choi}^{2}$ \\ ${ }^{1}$ Department of Nursing Science, Seoul Women's College of Nursing, Seoul, Korea \\ ${ }^{2}$ School of Liberal Arts and Science, Korea Aerospace University, Goyang, Korea
}

\begin{abstract}
This paper aims to examine the impact of satisfaction with family, friends, school, and government on life satisfaction, and to identify the impact of knowledge, attitude, and practice of sharing on life satisfaction. The fuzzy regression model was used to measure satisfaction levels by the passage of time. For satisfaction with family, friends, school, government, and life, the nursing students were asked to put down the minimum value in the interval. Sharing was measured by using instruments that divide sharing into individual and community levels. The estimated fuzzy regression model by using the $\alpha$-level set of the fuzzy number and least squares method implied that the satisfaction with family, friends, school, and government influenced life satisfaction and the spread of change in life satisfaction was influenced by satisfaction from individual sharing only. Therefore, it is important to form positive interactions by improving school satisfaction and sharing. As sharing positively affects life satisfaction, sharing activity was found to improve the reciprocal interactions of the students.
\end{abstract}

Keywords: Least squares method, Fuzzy regression model, Nursing students, Satisfaction

Received: May 13, 2019

Revised : Jun. 7, 2019

Accepted: Jun. 22, 2019

Correspondence to: Seung Hoe Choi (shchoi@kau.ac.kr)

(CThe Korean Institute of Intelligent Systems

cCThis is an Open Access article distributed under the terms of the Creative Commons Attribution Non-Commercial License (http://creativecommons.org/licenses/ by-nc/3.0// which permits unrestricted noncommercial use, distribution, and reproduction in any medium, provided the original work is properly cited.

\section{Introduction}

Life satisfaction demonstrates individuals' subjective sense of well-being resulting from overall and comprehensive evaluation of their lives, and it is influenced by subjective emotions related to their family identities, interpersonal relationships, the organization they belong to, and government [1]. Life satisfaction is important to nursing college students because it prevents burnout from study and reduces their sense of loneness, anxiety, stress, and depression [2]. Life satisfaction is important not only from the present perspective during nursing college days but also from the future perspective when the students lead lives as nurses. As it is important for nurses to interact with patients and medical personnel in carrying out their services, they are required to learn proper interaction in school [3, 4].

This study pays heed to interaction because, although they lead stable lives within the frame of family and school during school years, nursing students are vulnerable to the external environment. Also, they are in transition from a period when their basic needs are met by their family to a period when they acquire reciprocity from social relationships with people other than their family members, thereby laying a basis for forming interaction as nurses. Sharing is important for nurses because they share their skills and knowledge with other caregivers to treat their patients' illnesses. Sharing activity of a nurse is taking care of a sick person to become a healthy person. Therefore, nursing students need to learn sharing activity professionally. 
Sharing activity is reciprocal interaction [4, 5]. Sharing consists of knowledge, attitude, and practice [5, 6]. Experiencing the dynamics of the knowledge, attitude, and practice of sharing and seeing how they result in satisfaction is important in forming reciprocal interaction [7-9].

Since satisfaction changes with the passage of time, we uses fuzzy numbers that enable literal representation of satisfaction one feels as time passes or mathematical representation of satisfaction as an interval. Up until now, satisfaction surveys have represented satisfaction with a particular value at the present time, mostly using questionnaires or descriptive questions [10,11]. Although this can represent satisfaction well at the present time, such methods cannot measure change in satisfaction according to change in time, such as yesterday or a month ago. Because satisfaction changes depending on interaction, environment, and time, it is important to identify satisfaction that changes according to time. Analysis of satisfaction using the fuzzy set enables us to grasp change in satisfaction during a given period. Also, nursing science has had various studies using the fuzzy set. Im and Chee [12] used the fuzzy analysis that combines qualitative and quantitative analytical methods in understanding social and cultural contexts because nursing is not a field of study with a single solution but an area of learning that studies subjective meanings and behavior of human beings. As it also enables rational decision-making to enhance preference, fuzzy analysis is used for satisfaction research in nursing education [13-15].

In this paper we study to identify the impact of satisfaction with family, friends, school, and government on life satisfaction of nursing students, using fuzzy regression model. Also, the paper aims to look into the relationship between life satisfaction and sharing to identify reciprocal interaction. For this purpose, Section 2 introduces the method of estimating regression models using fuzzy indices, and Section 3 estimates the fuzzy return model for the satisfaction of life satisfaction.

\section{Method}

In this section, we briefly describe the procedure of the research and suggest the estimated fuzzy regression model for the life satisfaction of the nursing students.

\subsection{Research Planning and Procedure}

This study is based on a survey of nursing college students conducted to examine their satisfaction with family, friends, school, government, and life, and to identify the impact of
Table 1. Characteristics of the subjects $(N=128)$

\begin{tabular}{lcc}
\hline \multicolumn{1}{c}{ Variables } & Categories & $N(\%)$ \\
\hline Experience of & Yes & $64(50.0)$ \\
volunteer activity & No & $64(50.0)$ \\
Joining the club & Yes & $74(57.8)$ \\
& No & $54(42.2)$ \\
& Protestant & $41(32.0)$ \\
Religion & Catholic & $16(12.5)$ \\
& Buddhism & $4(3.1)$ \\
Age $(\mathrm{yr}), \mathrm{M} \pm$ S.D & No & $67(52.3)$ \\
\hline
\end{tabular}

knowledge, attitude, practice and satisfaction that comprise the individual and the community levels of sharing on life satisfaction. We distributed the questionnaires to 140 stuents and collected 140 copies of the questionnaire from September 1, 2016 to September 14, 2016. Excluding 12 copies that provided inaccurate information from the collected questionnaires, we analyzed data from 128 students.

The satisfaction levels in the questionnaires were divided into "very dissatisfied" $(51,60)$, "dissatisfied" $(61,70)$, "neither dissatisfied nor satisfied" $(71,80)$, "satisfied" $(81,90)$, and "very satisfied" $(91,100)$, from which the students were asked to select one interval and put down the minimum value in the interval. Based on the selected interval and the minimum value, fuzzy numbers about satisfaction were defined. An instrument to measure sharing was developed by Yoon et al. [7]. Sharing was measured on a 5 -point Likert scale, from 1 point for "Never" to 5 points for "Very often," with the questionnaire consisting of a total of 100 questions. Nursing college students who participated in the questionnaire survey of this study featured all female students, with their average age being 22.26 years old. Of the respondents, $52.3 \%$ were not religious, $57.8 \%$ joined clubs, and $50 \%$ participated in volunteer work as shown in Table 1.

\subsection{Fuzzy Set and Fussy Numbers}

The concept of fuzzy set was introduced to enable statistical analysis of incomplete data when the number of given data is insufficient or if the data are represented literally, and if the data cannot be used for classical data analysis due to their uncertain border or representation. Fuzzy sets are diversely used in regression analysis to conduct research on statistical models between the factors influencing social and natural results 
and the outcome and predictor variables [16-21]. In this study, satisfaction with family, friends, school, government, and life is represented with fuzzy numbers as follows. Dubios and Prade [17] defined the membership function $\mu_{A}(x)$ of LRfuzzy number $A=\left(a, l_{a}, r_{a}\right)_{L R}$ as below in order to describe the membership grades of fuzzy sets [22].

$$
\mu_{A}(x)= \begin{cases}L_{A}\left(\frac{a-x}{l_{a}}\right) & \text { for } 0 \leq a-x \leq l_{a}, \\ R_{A}\left(\frac{x-a}{r_{a}}\right) & \text { for } 0 \leq x-a \leq r_{a}, \\ 0 & \text { for otherwise. }\end{cases}
$$

Here the function $L_{A}\left(R_{A}\right)$ is monotonically increasing (decreasing) and satisfies

$$
L_{A}(0)=R_{A}(0)=1 \text { and } L_{A}(1)=R_{A}(1)=0 .
$$

Also, $a$ is called the mode of the LR-fuzzy number $A$, and $l_{a}$ and $r_{a}$ are called the spread of the left and right side of the LR-fuzzy number $A$, respectively. In particular, if the spread of the two sides is the same, it is indicated as $\left(a, a_{s}\right)_{L R}$, and if $L_{A}(x)=R_{A}(x)=1-x$, the LR-fuzzy number $A$ is referred to as a triangular fuzzy number, represented as $\left(a, l_{a}, r_{a}\right)_{T}$. The $\alpha$-level set of the LR-fuzzy number $A=\left(a, l_{a}, r_{a}\right)_{L R}$ is defined as $A(\alpha) \equiv\left\{x \mid \mu_{A}(x) \geq \alpha\right\}$, and $A^{*}(\alpha)=\left\{x \in X: \mu_{A}(x)\right.$ is called strong $\alpha$-level set. Here, if $0<\alpha \leq 1$ and $\alpha=$ $0, A(0)$ equals the closure of set $A^{*}(0)$. The $\alpha$-level set $A(\alpha)$ of the LR-fuzzy number $A$ is represented as an interval, like $\left[l_{A}(\alpha), r_{A}(\alpha)\right]$. The left and right end points of $\alpha$ level set are each represented as $l_{A}(\alpha)=a-l_{a} L_{A}^{-1}(\alpha)$ and $r_{A}(\alpha)=a-r_{a} R_{A}^{-1}(\alpha)$. Also, the 1-level set and 0-level set of LR-fuzzy number $A$ are expressed as $A(1)=\{a\}$ and $A(0)=\left[a-l_{a}, a-r_{a}\right]$, respectively.

\subsection{Fuzzy Regression Model}

In order to explain the linear relationships between satisfaction with family, friends, school, and government and satisfaction with life as represented by triangular fuzzy numbers we use the following fuzzy regression model:

$Y\left(X_{i}\right)=A_{0} \oplus A_{1} \otimes X_{i 1} \oplus \cdots \oplus A_{p} \otimes X_{i p} \oplus E_{i}, \quad i=1, \cdots, n$.

Here, the $j$ th component of $i$ th explanatory variable $X_{i j}=$ $\left(x_{i j}, s_{x_{i j}}\right)_{T}$, regression coefficient $A_{j}=\left(a_{j}, s_{a_{j}}\right)_{T}$, observation error $E_{i}=\left(e_{i}, s_{e_{i}}\right)_{T}$, and response variable $Y\left(X_{i}\right)=\left(y_{i}\right.$,
$\left.s_{y_{i}}\right)_{T}$ are triangular fuzzy numbers. And $\oplus$ and $\otimes$, respectively, indicate the addition and multiplication of fuzzy numbers.

In the fuzzy regression model (1), the $\alpha$-level set of the observed fuzzy number $Y_{i}$ is represented as $\left[y_{i}-L_{Y_{i}}{ }^{-1}(\alpha)\right.$, $\left.y_{i}-r_{y_{i}} R_{Y_{i}}{ }^{-1}(\alpha)\right]$, and the $\alpha$-level set of the predicted fuzzy number

$$
\begin{gathered}
A_{0} \oplus A_{1} \otimes X_{i 1} \oplus \cdots \oplus A_{p} \otimes X_{i p}, \\
{\left[\sum_{k=0}^{p} a_{k} x_{i k}-\sum_{k=0}^{p} l_{a k}(\alpha) l_{X_{i k}}(\alpha),\right.} \\
\left.\sum_{k=0}^{p} a_{k} x_{i k}+\sum_{k=0}^{p} r_{a_{k}}(\alpha) r_{X_{i k}}(\alpha)\right] .
\end{gathered}
$$

Here $x_{i 0}=1, l_{X_{i 0}}(\alpha)=1$, and $r_{X_{i 0}}(\alpha)=1$.

This study uses the least square method (2) and the five-stage estimation used by Jung et al. [22] in order to estimate the fuzzy regression coefficient $A_{k}(k=0, \cdots, 4)$ of the fuzzy regression model (1). Specifically, the fuzzy regression coefficient of the fuzzy regression model (1) can be estimated in the following manner by using the left and right end points of the $\alpha$-level set of the given fuzzy number

$$
\begin{gathered}
x\left(l_{Y_{i}}(\alpha), l_{X_{i 1}}(\alpha), l_{X_{i 2}}(\alpha), l_{X_{i 3}}(\alpha), l_{X_{i 4}}(\alpha)\right): \\
i=1, \cdots, 128\}
\end{gathered}
$$

and

$$
\begin{aligned}
& \left\{\left(r_{Y_{i}}(\alpha), r_{X_{i 1}}(\alpha), r_{X_{i 2}}(\alpha), r_{X_{i 3}}(\alpha), r_{X_{i 4}}(\alpha)\right):\right. \\
& \quad i=1, \cdots, 128\}
\end{aligned}
$$

respectively, and the least square method.

Stage 1: Estimate the mode $l_{A_{k}}(1)(k=0,1, \cdots, 4)$ of fuzzy regression coefficients.

Estimate the mode $\hat{l}_{A_{k}}$ (1) of fuzzy regression coefficients, using the value that minimizes

$$
\begin{aligned}
& \sum_{i=0}^{128}\left(r_{Y_{i}}(1)-\sum_{k=1}^{4} r_{A_{k}}(1) r_{X_{i k}}(1)\right)^{2} \text { or } \\
& \sum_{i=0}^{128}\left(l_{Y_{i}}(1)-\sum_{k=1}^{4} l_{A_{k}}(1) l_{X_{i k}}(1)\right)^{2} .
\end{aligned}
$$

Here $\hat{l}_{A_{k}}(1)=\hat{r}_{A_{k}}(1)$.

Stage 2: Estimate the end points, $l_{A_{k}}\left(\alpha^{*}\right)$ and $r_{A_{k}}\left(\alpha^{*}\right)$, of 
the $\alpha^{*}$-level set $A_{k}\left(\alpha^{*}\right)$ of fuzzy regression coefficients.

Regarding the random $\alpha^{*}$ that belongs to the open interval $(0,1)$, seek the intermediate estimators, $\bar{l}_{A_{k}}\left(\alpha^{*}\right)$ and $\bar{r}_{A_{k}}\left(\alpha^{*}\right)$, using

$$
\begin{aligned}
& \sum_{i=0}^{128}\left(l_{Y_{i}}\left(\alpha^{*}\right)-\sum_{k=1}^{4} l_{A_{k}}\left(\alpha^{*}\right) l_{X_{i k}}\left(\alpha^{*}\right)\right)^{2} \text { or } \\
& \sum_{i=0}^{128}\left(r_{Y_{i}}\left(\alpha^{*}\right)-\sum_{k=1}^{4} r_{A_{k}}\left(\alpha^{*}\right) r_{X_{i k}}\left(\alpha^{*}\right)\right)^{2} .
\end{aligned}
$$

Estimate the end point of $\hat{A}_{k}\left(\alpha^{*}\right)$, using the estimated values, $\bar{l}_{A_{k}}\left(\alpha^{*}\right)$ and $\bar{r}_{A_{k}}\left(\alpha^{*}\right)$, and

$$
\begin{aligned}
& \hat{l}_{A_{k}}\left(\alpha^{*}\right)=\operatorname{Min}\left\{\bar{l}_{A_{k}}\left(\alpha^{*}\right), \hat{l}_{A_{k}}(1)\right\} \text { and } \\
& \hat{r}_{A_{k}}\left(\alpha^{*}\right)=\operatorname{Min}\left\{\bar{r}_{A_{k}}\left(\alpha^{*}\right), \hat{r}_{A_{k}}(1)\right\} .
\end{aligned}
$$

Stage 3: Estimate the end points, $l_{A_{k}}(\alpha)$ and $r_{A_{k}}(\alpha),(\alpha \neq$ $\alpha^{*}$ ) of the $\alpha$-level set $\hat{A}_{k}(\alpha)$.

Regarding the random $\alpha$ that belongs to the open interval ( 0 , 1) and differs from $\alpha^{*}$, seek the intermediate estimators, $\bar{l}_{A_{k}}(\alpha)$ and $\bar{r}_{A_{k}}(\alpha)$, which are values that minimize

$$
\begin{aligned}
& \sum_{i=0}^{128}\left(l_{Y_{i}}(\alpha)-\sum_{k=1}^{4} l_{A_{k}}(\alpha) l_{X_{i k}}(\alpha)\right)^{2} \text { or } \\
& \sum_{i=0}^{128}\left(r_{Y_{i}}(\alpha)-\sum_{k=1}^{4} r_{A_{k}}(\alpha) r_{X_{i k}}(\alpha)\right)^{2} .
\end{aligned}
$$

Estimate the end point of $\hat{A}_{k}(\alpha)$, using $\hat{l}_{A_{k}}(1)$ found in Stage 1 , the end point of $\hat{A}_{k}\left(\alpha^{*}\right)$ estimated from Stage 2, and

$$
\hat{l}_{A_{k}}(\alpha)=\left\{\begin{array}{cl}
\operatorname{Max}\left\{\hat{l}_{A_{k}}\left(\alpha^{*}\right), \operatorname{Min}\left\{\bar{l}_{A_{k}}(\alpha), \hat{l}_{A_{k}}(1)\right\}\right\} & \text { if } \alpha^{*}<\alpha, \\
\operatorname{Min}\left\{\bar{l}_{A_{k}}(\alpha), \hat{l}_{A_{k}}\left(\alpha^{*}\right)\right\} & \text { if } \alpha^{*} \geq \alpha,
\end{array}\right.
$$

and

$$
\hat{r}_{A_{k}}(\alpha)=\left\{\begin{array}{cl}
\operatorname{Max}\left\{\hat{r}_{A_{k}}\left(\alpha^{*}\right), \operatorname{Min}\left\{\bar{r}_{A_{k}}(\alpha), \hat{r}_{A_{k}}(1)\right\}\right\} & \text { if } \alpha^{*}<\alpha, \\
\operatorname{Min}\left\{\bar{r}_{A_{k}}(\alpha), \hat{l}_{A_{k}}\left(\alpha^{*}\right)\right\} & \text { if } \alpha^{*} \geq \alpha .
\end{array}\right.
$$

Stage 4: Estimate the membership function $M_{\bar{A}_{k}}(\cdot)$ of the estimated regression coefficient $\hat{A}_{k}$.
Using the set of end points of the $\alpha$-level set estimated from Stage 1 to Stage 3,

$$
\begin{aligned}
& \left\{\left(\hat{l}_{A_{k}}\left(\alpha_{j}\right), \alpha_{j}\right): j=1, \cdots, s\right\} \text { and } \\
& \left\{\left(\hat{r}_{A_{k}}\left(\alpha_{j}\right), \alpha_{j}\right): j=1, \cdots, s\right\},
\end{aligned}
$$

the fuzzy number condition $M_{\bar{A}_{k}}\left(\hat{l}_{A_{k}}(1)\right)=M_{\bar{A}_{k}}\left(\hat{r}_{A_{k}}(1)\right)=$ 1 and $M_{\bar{A}_{k}}\left(\hat{l}_{A_{k}}(0)\right)=M_{\bar{A}_{k}}\left(\hat{r}_{A_{k}}(0)\right)=0$, and the least square method based on (3) and (4), estimate the membership function $M_{\bar{A}_{k}}(\cdot)$ of the estimated regression coefficient $\hat{A}_{k}$.

Stage 5: Estimate the predicted value $\hat{Y}\left(X_{i}\right)$ of the response variable.

Using the fuzzy regression coefficient $\hat{A}_{k}(k=0, \cdots, 4)$ investigated from Stage 4, we estimate the predicted value $\hat{Y}\left(X_{i}\right)$ of the response variable:

$$
\hat{Y}\left(X_{i}\right)=\hat{A}_{0} \oplus \hat{A}_{1} \otimes X_{i 1} \oplus \cdots \oplus \hat{A}_{4} \otimes X_{i 4} .
$$

\section{Fuzzy Regression Analysis for the Life Satis- faction}

In this section, we present the fuzzy regression model for the life satisfaction. The first is a model based on relational satisfaction, and the second is a model influenced by sharing.

\subsection{The Impacts of Family, Friends, School, and Govern- ment on Life Satisfaction}

Data on satisfaction were represented not as a particular value but as fuzzy numbers, considering satisfaction up to the present (Table 2). To estimate the fuzzy regression model about life satisfaction represented as fuzzy numbers, we conducted estimations following Stage 1 through Stage 5. The fuzzy regression model $\left(\hat{Y}_{w i}\left(X_{i}\right)\right)$ with consideration of an intercept and the fuzzy regression model $\left(\hat{Y}_{w o i}\left(X_{i}\right)\right)$ without consideration of an intercept according to the estimation methods are represented as follows:

$$
\begin{aligned}
\hat{Y}_{w i}\left(X_{i}\right)= & (18.961,4.404)_{T} \oplus 0.210 \otimes X_{i 1} \oplus 0.099 \otimes X_{i 2} \\
& \oplus 0.354 \otimes X_{i 3} \oplus(0.143,0.02)_{T} \otimes X_{i 4}, \\
\hat{Y}_{w o i}\left(X_{i}\right)= & 0.272 \otimes X_{i 1} \oplus(0.199,0.015)_{T} \otimes X_{i 2} \\
& \oplus(0.39,0.005)_{T} \otimes X_{i 3} \oplus(0.167,0.03)_{T} \otimes X_{i 4} .
\end{aligned}
$$

According to the estimated fuzzy regression model (5), the mode of the life satisfaction of nursing students were influenced 
Table 2. Impacts of family, friends, school, government, and sharing on life satisfaction $(N=128)$

\begin{tabular}{lrcclcc}
\hline Number & & 1 & 2 & $\ldots$ & 127 & 128 \\
\hline & Life $\left(Y_{i}\right)$ & $(77.5,2.5)_{T}$ & $(75.5,4.5)_{T}$ & $\ldots$ & $(80,1)_{T}$ & $(80,0)_{T}$ \\
Observed & Family $\left(X_{i 1}\right)$ & $(67.5,2.5)_{T}$ & $(85.5,4.5)_{T}$ & $\ldots$ & $(75.5,4.5)_{T}$ & $(100,0)_{T}$ \\
Satisfaction & Friend $\left(X_{i 2}\right)$ & $(77.5,2.5)_{T}$ & $(87.5,2.5)_{T}$ & $\ldots$ & $(97.5,2.5)_{T}$ & $(100,0)_{T}$ \\
& School $\left(X_{i 3}\right)$ & $(75.5,4.5)_{T}$ & $(90,0)_{T}$ & $\ldots$ & $(55.5,4.5)_{T}$ & $(80,0)_{T}$ \\
& Government $\left(X_{i 4}\right)$ & $(70,0)_{T}$ & $(75,5)_{T}$ & $\ldots$ & $(55.5,4.5)_{T}$ & $(75.5,4.5)_{T}$ \\
Predicted & $\hat{Y} w i\left(X_{i}\right)$ & $(77.6,8.2)_{T}$ & $(88.2,7.7)_{T}$ & $\ldots$ & $(72.1,8.9)_{T}$ & $(89,6.5)_{T}$ \\
satisfaction & $\hat{Y} w o i\left(X_{i}\right)$ & $(74.9,5.2)_{T}$ & $(88.4,5.7)_{T}$ & $\ldots$ & $(70.1,6.6)_{T}$ & $(90.9,4.0)_{T}$ \\
& Knowledge $\left(p_{i 1}\right)$ & 3.25 & 3.75 & $\ldots$ & 3.5 & 4.0 \\
Individual & Attitude $\left(p_{i 2}\right)$ & 3.2 & 2.8 & $\ldots$ & 3.89 & 3.96 \\
& Practice $\left(p_{i 3}\right)$ & 2.78 & 3.33 & $\ldots$ & 2.72 & 3.67 \\
Community & Knowledge $\left(c_{i 1}\right)$ & 3.86 & 3.77 & $\ldots$ & 3.64 & 3.73 \\
& Attitude $\left(c_{i 2}\right)$ & 3.11 & 3.96 & $\ldots$ & 3.89 & 3.96 \\
Sharing & Practice $\left(c_{i 3}\right)$ & 3.0 & 3.88 & $\ldots$ & 3.38 & 3.88 \\
satisfaction & Individual $\left(s_{i 1}\right)$ & 2.67 & 2.33 & $\ldots$ & 3.33 & 1.67 \\
Predicted & Community $\left(s_{i 2}\right)$ & 3.59 & 4.12 & $\ldots$ & 3.82 & 4.06 \\
satisfaction & Individual $\left(\hat{Y} p_{i}\right)$ & $(83.3,5.1)_{T}$ & $(85.7,5.2)_{T}$ & & $(84.4,4.9)_{T}$ & $(86.1,4.3)_{T}$ \\
& Community $\left(\hat{Y} c_{i}\right)$ & $(80.6,6.4)_{T}$ & $(80.6,2.8)_{T}$ & & $(83.3,7.0)_{T}$ & $(84.7,6.6)_{T}$ \\
\hline & Sharing satisfaction $\left(\hat{Y} s_{i}\right)$ & $(80.6,2.8)_{T}$ & $(82.6,2.8)_{T}$ & & $(86.2,2.8)_{T}$ & $(78.9,2.7)_{T}$ \\
\hline
\end{tabular}

by satisfaction with family $\left(X_{i 1}\right)$, friends $\left(X_{i 2}\right)$, school $\left(X_{i 3}\right)$, and government $\left(X_{i 4}\right)$. Also, change in satisfaction with government had a greater impact on change in life satisfaction than other variables as shown in Table 2.

\subsection{The Impact of Sharing on Life Satisfaction}

This paper used the fuzzy regression model to identify life satisfaction represented by fuzzy numbers and statistical relations between life satisfaction and sharing at individual and community levels. To this end, we estimated the fuzzy regression model by applying the $\alpha$ level set $\left[y_{i}-l_{y_{i}} L_{Y_{i}}{ }^{-1}(\alpha)\right.$, $\left.y_{i}-r_{y_{i}} R_{Y_{i}}{ }^{-1}(\alpha)\right]$ of the observed fuzzy number $Y_{i}$ and the $\alpha$-level set

$$
\begin{aligned}
& {\left[\sum_{k=0}^{p} a_{k} x_{i k}-\sum_{k=0}^{p} l_{a k}(\alpha) x_{i k},\right.} \\
& \left.\quad \sum_{k=0}^{p} a_{k} x_{i k}+\sum_{k=0}^{p} r_{a_{k}}(\alpha) x_{i k}\right] \quad(0 \leq \alpha<1)
\end{aligned}
$$

of the predicted fuzzy number $A_{0}+A_{1} x_{i 1}+\cdots+A_{p} x_{i p}$ according to the five-stage estimation method as already presented in the research methods. Here $x_{i 0}=1$.

First, the impact of the knowledge $\left(p_{i 1}\right)$, attitude $\left(p_{i 2}\right)$, and practice $\left(p_{i 3}\right)$ of individual sharing on life satisfaction of the nursing students is represented as follows:

$$
\begin{aligned}
\hat{Y}_{w i}\left(p_{i}\right)= & (61.198,3.012)_{T} \oplus 2.587 \otimes p_{i 1} \oplus(1.583,0.62)_{T} \\
& \otimes p_{i 2} \oplus(0.184,0.382)_{T} \otimes p_{i 3} .
\end{aligned}
$$

Second, the impact of knowledge $\left(c_{i 1}\right)$, attitude $\left(c_{i 2}\right)$, and practice $\left(c_{i 3}\right)$ of community sharing on on life satisfaction of the nursing students is represented as follows:

$$
\begin{aligned}
\hat{Y}_{w i}\left(c_{i}\right)= & (49.535,5.065)_{T} \oplus 4.242 \otimes c_{i 1} \oplus 4.545 \otimes c_{i 2} \\
& \oplus(3.099,0.019)_{T} \otimes c_{i 3} .
\end{aligned}
$$

The knowledge, attitude, and practice of sharing all had a positive impact on life satisfaction at both individual and community levels. The estimated fuzzy regression model (6) shows that attitude and practice of sharing at the individual level and practice of sharing at the community level had an impact on satisfaction. 


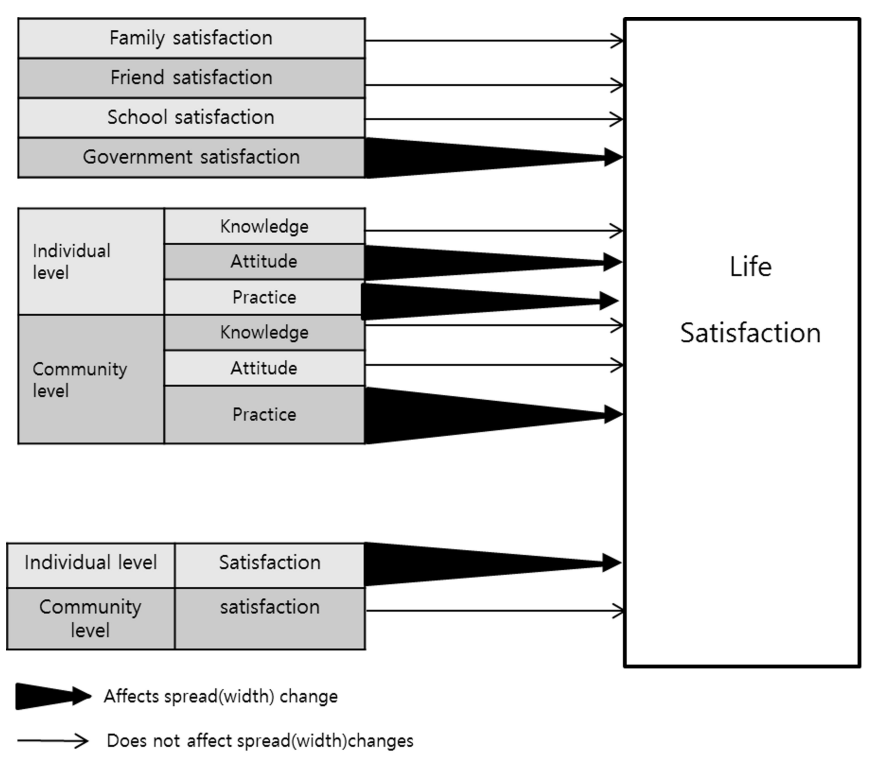

Figure 1. The impact of sharing on life satisfaction.

The results of the fuzzy regression analysis of the impact of satisfaction from individual sharing $\left(s_{i 1}\right)$ and satisfaction from community sharing $\left(s_{i 2}\right)$ on life satisfaction are represented as follows:

$$
\begin{aligned}
\hat{Y}_{w i}\left(s_{i}\right)= & (47.150,2.59)_{T} \oplus(3.949,0.068)_{T} \otimes s_{i 1} \\
& +6.371 \otimes\left(s_{i 2}\right) .
\end{aligned}
$$

The estimated fuzzy regression model (7) explains that satisfaction from sharing at both individual and community levels has a positive impact on life satisfaction of the nursing students and that change in satisfaction is affected by satisfaction from individual sharing as shown in Table 2.

The study of width in the fuzzy regression model is a difference from the classical regression model. Figure 1 illustrates the variables used in this paper and the results for the fuzzy return model estimated in Section 3. The breadth of life satisfaction is only influenced by the satisfaction of the government, and the practice of sharing is affecting the breadth of life satisfaction, whether it is individuals or communities. Figure 1 illustrates that the satisfaction of the individual sharing affects the change in satisfaction of life.

\section{Conclusion}

Life satisfaction of nursing college students was influenced by their satisfaction with family, friends, school, and government, with satisfaction with school having the greatest impact.
Regarding the relations between sharing and life satisfaction, the practice of sharing had the greatest impact at the individual level, and the knowledge of sharing and attitude toward sharing had an impact at the community level. Regarding satisfaction from sharing, satisfaction from community sharing had the greatest impact on life satisfaction. The spread of change in life satisfaction was influenced by satisfaction from individual sharing only.

When we measured satisfaction according to change in time, life satisfaction received the most influence from satisfaction with school. Therefore, it is necessary for nursing colleges to lay a basis for making positive interaction by improving students' satisfaction with school. Also, because sharing activity for a certain period enhances life satisfaction, it is important for nursing students to improve their life satisfaction in social contexts through various sharing activities, thereby improving their abilities in have reciprocal interaction.

This study confirmed that the satisfaction of the life of nursing students was affected by the relative satisfaction and sharing. Based on this study, we can continue our study with university students who study other majors and the adults. Also, there were many cases in which the spread of the fuzzy numbers was zero (0) in this study when the numbers were estimated using the fuzzy regression model to examine life satisfaction of nursing students. As such, there were big errors in some cases when life satisfaction was estimated by using the least square method. Therefore, future studies need to make estimates using estimators that are robust and resistant to outliers.

\section{Conflict of Interest}

No potential conflict of interest relevant to this article was reported.

\section{Acknowledgments}

This work was supported by the National Research Foundation of Korea (NRF) grant funded by the Korea government (MSIT) (No. 2017R1D1A1B03039559).

\section{References}

[1] W. Jeong and H. Kim, "The effects of career calling on the life satisfaction among college students: the mediating effects of social support and planned happenstance skills," Korean Journal of Youth Studies, vol. 24, no. 2, pp. 445- 
472, 2017. http://doi.org/10.21509/KJYS.2017.01.24.2. 445

[2] H. O. Jeon, "The influence of nursing professionalism, academic failure tolerance and social self-efficacy on college life satisfaction among nursing students," Journal of Korean Academic Society of Nursing Education, vol. 22, no. 2, pp. 171-181, 2016. https://doi.org/10.5977/jkasne. 2016.22.2.171

[3] G. Gilman, E. S. Huebner, L. Tian, N. Park, J. O’Byrne, M. Schiff, D. Sverko, and H. Langknecht, "Cross-national adolescent multidimensional life satisfaction reports: analyses of mean scores and response style differences," Journal of Youth and Adolescence, vol. 37, no. 2, pp. 142-154, 2008. https://doi.org/10.1007/s10964-007-9172-8

[4] M. A. Whitley, "A Draft conceptual framework of relevant theories to inform future rigorous research on student service-learning outcomes," Michigan Journal of Coтmunity Service Learning, vol. 20, no. 2, pp. 19-40, 2014.

[5] H. Y. Koo, H. S. Park, and E. H. Jang, "Satisfaction with life and it's predictors of Korean adolescents," Journal of Korean Academy of Nursing, vol. 36, no. 1, pp. 151-158, 2006. https://doi.org/10.4040/jkan.2006.36.1.151

[6] D. T. Shek, L. Yu, F. K. Wu, X. Zhu, and K. H. Chan, "A 4-year longitudinal study of well-being of Chinese university students in Hong Kong," Applied Research in Quality of Life, vol. 12, no. 4, pp. 867-884, 2017. https: //doi.org/10.1007/s11482-016-9493-4

[7] H. Yoon, S. Choi, and H. Kim, "A study on the index and satisfaction of the sharing," Information: An International Interdisciplinary Journal, vol. 20, no. 8B, pp. 6087-6094, 2017.

[8] M. Ottoni-Wilhelm, D. B. Estell, and N. H. Perdue, "Rolemodeling and conversations about giving in the socialization of adolescent charitable giving and volunteering," Journal of Adolescence, vol. 37, no. 1, pp. 53-66, 2014. https://doi.org/10.1016/j.adolescence.2013.10.010

[9] Y. L. Ferguson, T. Kasser, and S. Jahng, "Differences in life satisfaction and school satisfaction among adolescents from three nations: the role of perceived autonomy support," Journal of Research on Adolescence, vol. 21, no. 3, pp. 649-661, 2011. https://doi.org/10.1111/j.15327795.2010.00698.x
[10] M. S. Birkeland, K. Breivik, and B. Wold, "Peer acceptance protects global self-esteem from negative effects of low closeness to parents during adolescence and early adulthood," Journal of Youth and Adolescence, vol. 43, no. 1, pp. 70-80, 2014. https://doi.org/10.1007/s10964-0139929-1

[11] M. D. Mathad, S. K. Rajesh, and B. Pradhan, "Spiritual well-being and its relationship with mindfulness, self-compassion and satisfaction with life in baccalaureate nursing students: a correlation study," Journal of Religion and Health, vol. 58, no. 2, pp. 554-565, 2019. https://doi.org/10.1007/s10943-017-0532-8

[12] E. O. Im and W. Chee, "Fuzzy logic and nursing," Nursing Philosophy, vol. 4, no. 1, pp. 53-60, 2003. https://doi.org/ 10.1046/j.1466-769X.2003.00116.x

[13] B. J. Weiner, S. R. Jacobs, L. M. Minasian, and M. J. Good, "Organizational designs for achieving high treatment trial enrollment: a fuzzy-set analysis of the community clinical oncology program," Journal of Oncology Practice, vol. 8, no. 5, pp. 287-291, 2012. https://doi.org/10.1200/JOP. 2011.000507

[14] S. Topaloglu and H. Selim, "Nurse scheduling using fuzzy modeling approach," Fuzzy Sets and Systems, vol. 161, no. 11, pp. 1543-1563, 2010. https://doi.org/10.1016/j.fss. 2009.10 .003

[15] M. Sun, T. Li, B. Ji, Y. Jiao, and S. Tang, "Evaluation research on assessment of clinical nursing teaching quality based on fuzzy comprehensive evaluation method," Journal of Convergence Information Technology, vol. 7, no. 8, pp. 82-91, 2012. https://doi.org/10.4156/jcit.vol7.issue8. 10

[16] P. Diamond, "Fuzzy least squares," Information Sciences, vol. 46, no. 3, pp. 141-157, 1988. https://doi.org/10.1016/ 0020-0255(88)90047-3

[17] D. Dubois and H. Prade, "Fuzzy real algebra: some results," Fuzzy Sets and Systems, vol. 2, no. 4, 327-348, 1979. https://doi.org/10.1016/0165-0114(79)90005-8

[18] S. H. Choi and J. J. Buckley, "Fuzzy regression using least absolute deviation estimators," Soft Computing, vol. 12, no. 3, pp. 257-263, 2008. https://doi.org/10.1007/s00500007-0198-3 
[19] S. H. Choi and J. H. Yoon, "General fuzzy regression using least squares method," International Journal of Systems Science, vol. 41, no. 5, pp. 477-485, 2010. https://doi.org/ 10.1080/00207720902774813

[20] W. J. Lee, H. Y. Jung, J. H. Yoon, and S. H. Choi, "Analysis of variance for fuzzy data based on permutation method," International Journal of Fuzzy Logic and Intelligent Systems, vol. 17, no. 1, pp. 43-50, 2017. https://doi.org/10.5391/IJFIS.2017.17.1.43

[21] I. K. Kim, W. J. Lee, J. H. Yoon, and S. H. Choi, "Fuzzy regression model using trapezoidal fuzzy numbers for re-auction data," International Journal of Fuzzy Logic and Intelligent Systems, vol. 16, no. 1, pp. 72-80, 2016. https://doi.org/10.5391/IJFIS.2016.16.1.72

[22] H. Y. Jung, J. H. Yoon, and S. H. Choi, "Fuzzy linear regression using rank transform method," Fuzzy Sets and Systems, vol. 274, pp. 97-108, 2015. https://doi.org/10. 1016/j.fss.2014.11.004

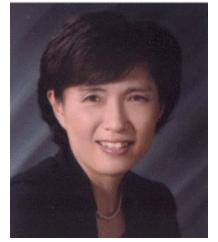

Hee Sang Yoon received the Ph.D. degree in Nursing from Ewha Womans University in Korea and she received master's degree of Public health from University of Glasgow in UK. Since 2005, she has been an Professor with Department of Nursing, Seoul Women's College of Nursing, Korea. Her research interests includes sharing, health promotion and community health nursing.

E-mail: viva826@hanmail.net

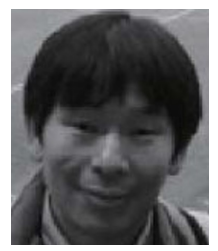

Seung Hoe Choi obtained his Ph.D. degree in Mathematical Statistics from Yonsei University, Korea in 1994. Since 1996, he is currently full professor of Korea Aerospace University. His main research interests are mathematical prediction method using the soft computing and statistical prediction in sports like soccer, baseball and basketball.

E-amil: shchoi@kau.ac.kr 